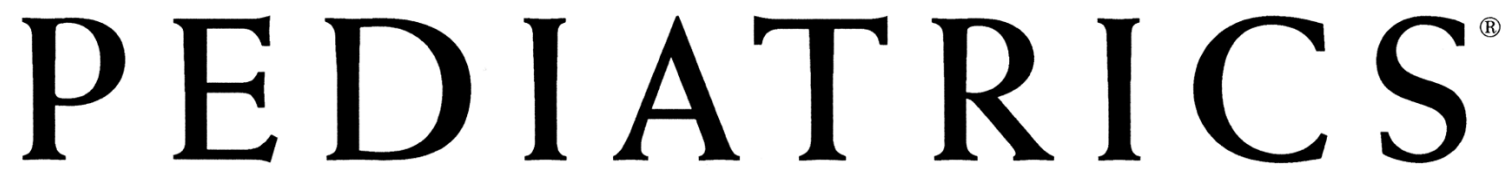

OFFICIAL JOURNAL OF THE AMERICAN ACADEMY OF PEDIATRICS

\author{
Self-Hypnosis for Management of Chronic Dyspnea in Pediatric Patients \\ Ran D. Anbar \\ Pediatrics 2001;107;21- \\ DOI: $10.1542 /$ peds.107.2.e21
}

This information is current as of October 13, 2006

The online version of this article, along with updated information and services, is located on the World Wide Web at:

http://www.pediatrics.org/cgi/content/full/107/2/e21

PEDIATRICS is the official journal of the American Academy of Pediatrics. A monthly publication, it has been published continuously since 1948. PEDIATRICS is owned, published, and trademarked by the American Academy of Pediatrics, 141 Northwest Point Boulevard, Elk Grove Village, Illinois, 60007. Copyright @ 2001 by the American Academy of Pediatrics. All rights reserved. Print ISSN: 0031-4005. Online ISSN: 1098-4275.

\title{
American Academy of Pediatrics
}




\title{
Self-Hypnosis for Management of Chronic Dyspnea in Pediatric Patients
}

\author{
Ran D. Anbar, MD
}

ABSTRACT. Introduction. Hypnotherapy can be useful in the management of anxiety, discomfort, and psychosomatic symptoms, all of which may contribute to a complaint of dyspnea. Therefore, instruction in self-hypnosis was offered to 17 children and adolescents with chronic dyspnea, which had not resolved despite medical therapy, and who were documented to have normal lung function at rest. This report documents the result of this intervention.

Methods. A retrospective chart review identified all patients followed by a single pediatric pulmonologist (R.D.A.), with a chief complaint of chronic dyspnea from April 1998 through December 1999. These patients had been evaluated and treated for medical diseases according to their history, physical examination, and laboratory investigations. The pulmonologist offered to teach selfhypnosis to all of these patients, who comprise the cohort in this report.

Chronic dyspnea was defined as recurrent difficulty breathing or shortness of breath at rest or with exertion, which had existed for at least 1 month in patients who had not suffered within a month from an acute pulmonary illness.

The pulmonologist was trained in hypnosis through his attendance at three 20-hour workshops.

Hypnosis was taught to individual patients in 1 or two 15- to 45-minute sessions. Patients were taught hypnotic self-induction techniques and imagery to achieve relaxation. Additionally, imagery relating to dyspnea was developed by coaching patients to change their imagined lung appearance from a dyspneic to a healthy state. Patients were encouraged to practice self-hypnosis regularly and to use lung imagery to eliminate dyspnea if it occurred.

Results. Seventeen patients (13 males and 4 females) with chronic dyspnea were documented to have normal pulmonary function at rest. Their mean age was 13.4 years (range: 8-18 years). Twelve of the 17 previously were diagnosed with other conditions, such as allergies, asthma, and gastroesophageal reflux. Fifteen of the 17 manifested at least 1 other symptom associated with their dyspnea, including an anxious appearance (4 patients); chest tightness or pain (5); cough (4); wheeze (3); difficulty with inspiration (2); hyperventilation (1); inspiratory noise, such as stridor, gasping, rasping, or squeak (8); dizziness (1); feeling something is stuck in the throat (2); parasthesias (4); and tachycardia (3).

Of the 17 patients, 2 complained of dyspnea at rest only, 13 complained of dyspnea with activity only, and 2

\footnotetext{
From the Department of Pediatrics, State University of New York Upstate Medical University, Syracuse, New York.

Received for publication Jun 23, 2000; accepted Sep 5, 2000

Reprint requests to (R.D.A.) Department of Pediatrics, State University of New York Upstate Medical University, 750 E Adams St, Syracuse, NY 13210. E-mail: anbarr@mail.upstate.edu

PEDIATRICS (ISSN 0031 4005). Copyright (C) 2001 by the American Academy of Pediatrics.
}

complained of dyspnea both at rest and with activity. Nine patients reported that they frequently needed to discontinue their physical activity because of dyspnea. The mean duration of their dyspnea before learning selfhypnosis was 2 years (range: 1 month to 5 years). The dyspnea was of $<6$ months duration for 4 of the patients.

For 9 of the 17 patients a potential psychosocial association with their dyspnea was identified: 3 developed symptoms at school only; 2 with exercise during competitive races only; 3 after a major disagreement between their parents; and 1 developed symptoms each time his family moved to a new neighborhood.

Before presentation, 7 of the 17 patients received chronic inhaled antiinflammatory therapy, and 3 were using inhaled albuterol, as needed.

All 17 patients had normal physical examinations, with the exception of healed scars on the chest and abdomen of 1 patient, a repaired cleft palate in 1 patient, and rhinitis in another. Four of the $\mathbf{1 7}$ underwent pulmonary function testing before and after exercise, 6 had chest radiographs, and 3 had electrocardiograms. All of these tests were normal.

A patient with a history of psychogenic cough declined to learn self-hypnosis. Thirteen of the remaining 16 patients were taught to use self-hypnosis in 1 session. A second session was provided to 3 patients within 2 months.

Thirteen of the 16 patients reported their dyspnea and any associated symptoms had resolved within 1 month of their final hypnosis instruction session. Eleven believed that resolution of their dyspnea was attributable to hypnosis, because their symptoms cleared immediately after they received hypnosis instruction ( 5 patients) or with its regular use (6). Two did not attribute resolution of dyspnea to hypnosis because they did not use it at home. The remaining 3 reported that their dyspnea had improved.

Patients were followed for a mean 9 months (range: 2-15 months) after their final hypnosis session. Ten of the 16 regularly used self-hypnosis at home for at least 1 month after the final hypnosis session. There was no recurrence of dyspnea, associated symptoms, or onset of new symptoms in patients in whom the dyspnea resolved.

Under supervision of the pediatric pulmonologist, 2 of 7 patients discontinued their chronic antiinflammatory therapy when they became asymptomatic after hypnosis. Subsequently, their pulmonary function remained normal.

Discussion. Use of self-hypnosis was associated with resolution of dyspnea in 13 of 16 patients who had normal pulmonary function. The improvement may have been attributable to physiologic effects of hypnosis. Furthermore, some of the dyspnea-associated symptoms in these patients were suggestive of anxiety disorders, which are amenable to therapy with hypnosis.

Ten patients complained of difficulty with inspiration or made an inspiratory noise when they were dyspneic. It was suspected that many of these patients were suffering 
from vocal cord dysfunction, which is amenable to therapy with hypnosis. Because use of hypnosis was associated with rapid resolution of symptoms of most of these patients, there was no need to undertake additional investigations involving provocation of symptoms or laryngoscopic evaluation.

Although resolution or improvement of dyspnea cannot be attributed solely to hypnosis in this report, it seems that introduction of hypnosis was a key factor in view of the average 2-year duration of symptoms before its utilization. For the 4 patients who were symptomatic for a short duration (ie, for $<6$ months), it is possible that their improvement was caused by factors independent of hypnotherapy, such as change of weather.

Conclusion. A controlled prospective study using serial objective measures is recommended to substantiate this reported dramatic improvement of chronic dyspnea in pediatric patients who were taught self-hypnosis. Pediatrics 2001;107(2). URL: http://www.pediatrics.org/ cgi/content/full/107/2/e21; dyspnea, hypnosis, spirometry, anxiety disorder, vocal cord dysfunction.

$\mathrm{T}$ The most common causes of chronic dyspnea are respiratory disorders, such as asthma, cystic fibrosis, and interstitial lung disease. ${ }^{1}$ Nonpulmonary causes of dyspnea include deconditioning, gastroesophageal reflux, cardiovascular disease, and psychological factors..$^{1,2}$

Children and adolescents sometimes have incomplete resolution of chronic dyspnea despite receiving appropriate medical therapy. Because such patients can respond to psychological interventions, ${ }^{1}$ since April 1998 such patients presenting to a pediatric pulmonary center were offered the opportunity to learn self-hypnosis to help control their symptoms.

Although there is no generally accepted definition of hypnosis, ${ }^{3-6}$ in practice it can be useful to think of hypnosis as an altered state of consciousness and hypnotherapy as a treatment modality using hypnosis to achieve a therapeutic goal. ${ }^{3}$ Hypnosis is useful in altering thoughts, feelings, expectations, attitudes, behavior, and perception.., 6 Therefore, hypnotherapy can be useful in the management of anxiety, discomfort, and psychosomatic symptoms, ${ }^{6}$ all of which may contribute to a complaint of dyspnea.

This report summarizes the efficacy of self-hypnosis for pediatric patients with chronic dyspnea who were found to have normal lung function at rest.

\section{METHODS}

A retrospective chart review identified all patients followed by a single pediatric pulmonologist (R.D.A.), with a chief complaint of chronic dyspnea from April 1998 through December 1999, who were documented to have normal baseline pulmonary function at rest. These patients had been evaluated and treated for medical diseases according to their history, physical examination, and laboratory investigations. The pulmonologist offered to teach selfhypnosis to all of these patients, who comprise the cohort in this report.

Chronic dyspnea was defined as recurrent difficulty breathing or shortness of breath at rest or with exertion, which had existed for at least 1 month in patients who had not suffered within a month from an acute pulmonary illness.

Patients were defined as having normal pulmonary function at rest if their hemoglobin saturation as measured by pulse oximetry was $>95 \%$; if their forced vital capacity and forced expiratory volume in 1 second were $>80 \%$ of predicted; if their forced expiratory flow, $25 \%$ to $75 \%$ vital capacity was $>60 \%$ of predicted; and if they did not demonstrate significant bronchodilation 10 minutes after administration of $180 \mu \mathrm{g}$ of albuterol by meter dosed inhaler (eg, a $>10 \%$ improvement in forced vital capacity or forced expiratory volume in 1 second, or a $>20 \%$ improvement in forced expiratory flow, $25 \%$ to $75 \%$ vital capacity). Spirometric testing was performed according to published standards. ${ }^{7}$ Predicted values were calculated based on sex, race, height, and age. ${ }^{8}$

The pulmonologist was trained in hypnosis through his attendance in three 20-hour workshops sponsored by the Society for Developmental and Behavioral Pediatrics and the American Society of Clinical Hypnosis.

Hypnosis was taught to individual patients in one or two 15- to 45-minute sessions. The hypnosis instruction was not standardized and hypnotizability was not formally assessed. In the first session, patients were taught a hypnotic self-induction technique, imagery to achieve relaxation, and imagery intended to help relieve their dyspnea. For example, induction was achieved by the technique of arm levitation ${ }^{4}$; and relaxation was accomplished by asking patients to imagine what might be perceived by each of the 5 senses in a relaxing place. Specific imagery relating to the dyspnea was developed with the assistance of the patients: they were asked to describe the imagined appearance of their lungs when dyspnea was present and absent. They then were coached to change their lung appearance from a dyspneic state to how they imagined their lungs to appear in a normal, healthy state. Patients were encouraged to practice the self-hypnosis relaxation techniques on a daily basis and to use lung imagery to reduce or eliminate dyspnea if it occurred. A second session was requested by some patients for whom the dyspnea only partially resolved after initial instruction in self-hypnosis. At the second session, self-hypnosis techniques were reviewed and additional imagery to help control dyspnea was developed with the patients' input.

Because this report describes a retrospective chart review without identification of patients, it was exempt from review by an institutional review board.

\section{RESULTS}

Seventeen patients (13 males and 4 females) with chronic dyspnea were documented to have normal pulmonary function at rest during the 20-month review period. Their mean age was 13.4 years (range: 8-18 years). Twelve of the 17 patients previously were diagnosed by their referring physicians with other conditions, including 4 who had more than one diagnosis (Table 1). Fifteen of the 17 patients manifested other symptoms associated with their dyspnea, including 9 patients with more than one additional symptom (Table 2).

Of the 17 patients, 2 complained of dyspnea at rest only, 13 complained of dyspnea with activity only, and 2 complained of dyspnea both at rest and with activity. Nine of the patients reported that they frequently needed to discontinue their physical activity because of dyspnea. The mean duration of their dyspnea before learning self-hypnosis was 2 years

TABLE 1. Diagnoses of Patients With Normal Baseline Lung Function

\begin{tabular}{lc}
\hline & $\begin{array}{c}\text { Number of } \\
\text { Patients }\end{array}$ \\
\hline Acute lymphocytic leukemia & 1 \\
Allergies & 5 \\
Asthma & 5 \\
Attention deficit hyperactivity disorder & 1 \\
Cleft palate & 1 \\
Cystic fibrosis & 1 \\
Gastroesophageal reflux & 2 \\
Growth hormone deficiency & 1 \\
Hereditary spherocytosis & 1 \\
Sinusitis & 1 \\
Wilm's tumor & 1 \\
\hline
\end{tabular}


TABLE 2. Symptoms Associated With Dyspnea

\begin{tabular}{lc}
\hline & $\begin{array}{c}\text { Number of } \\
\text { Patients }\end{array}$ \\
\hline Anxious appearance & 4 \\
Chest tightness/pain & 5 \\
Cough & 4 \\
Dizziness & 1 \\
Feeling something is stuck in the throat & 2 \\
Difficulty with inspiration & 2 \\
Hyperventilation & 1 \\
Inspiratory noise* & 8 \\
Tachycardia & 3 \\
Tingling of extremities & 4 \\
Wheeze & 3 \\
\hline
\end{tabular}

* Including stridor, gasping, rasping, and a squeak.

(range: 1 month to 5 years). The dyspnea was of $<6$ months duration for 4 of the patients.

For 9 of the 17 patients a potential psychosocial association with their dyspnea was identified: three developed symptoms at school only; 2 with exercise during competitive races only; 3 after a major disagreement between their parents; and 1 developed symptoms each time his family moved to a new neighborhood.

Before presentation, 7 of the 17 patients received chronic inhaled antiinflammatory therapy, and 3 were using inhaled albuterol, as needed.

All 17 patients had normal physical examinations, with the exception of healed scars on the chest and abdomen of the patient with Wilm's tumor, a repaired cleft palate in 1 patient, and rhinitis in another. Four of the 17 patients underwent pulmonary function testing before and after exercise, 6 had chest radiographs, and 3 had an electrocardiogram. All of these tests were normal.

A patient with a history of psychogenic cough declined to learn self-hypnosis, speech therapy, or undergo counseling. She was subsequently lost to follow-up. Thirteen of the remaining 16 patients were taught to use self-hypnosis in 1 session. A second session was provided to 3 patients within 2 months.

Thirteen of the 16 patients reported that their dyspnea and any associated symptoms had resolved within 1 month of their final hypnosis instruction session. Eleven believed that resolution of their dyspnea was because of hypnosis, because their symptoms cleared immediately after its use at the center (5 patients) or with regular use (6). Two did not attribute resolution of dyspnea to hypnosis because they did not use it at home. The remaining 3 reported that their dyspnea had improved.

Patients were followed for a mean 9 months (range: 2-15 months) after the final hypnosis session. Nine of the patients were seen for medical management by the pediatric pulmonologist approximately every 3 months after their final hypnosis session. The remaining 7 patients were not seen and were contacted by telephone on one occasion by the author for follow-up. Other than the pulmonologist's acknowledgment of their successful use of hypnosis, patients received no further reinforcement of their hypnosis skills during either personal or telephone follow-up.
Ten of the 16 patients regularly used self-hypnosis at home for at least 1 month after the final hypnosis session. There was no recurrence of dyspnea, associated symptoms, or onset of new symptoms in patients in whom the dyspnea resolved.

Two of 7 patients discontinued their chronic antiinflammatory therapy when they become asymptomatic after hypnosis, and another discontinued her albuterol therapy, under supervision of the pulmonologist. Subsequently, their pulmonary function remained normal.

\section{DISCUSSION}

In this report, use of self-hypnosis was associated with resolution of dyspnea in 13 of 16 patients who had normal pulmonary function. The improvement may have been attributable to physiologic effects of hypnosis. ${ }^{9}$ Further, some of the dyspnea-associated symptoms in these patients were suggestive of a panic attack or choking phobia because of an anxiety disorder ${ }^{10,11}$ both of which are amenable to therapy with hypnosis. ${ }^{3,4}$ For example, some patients complained of symptoms characteristic of anxiety, such as chest tightness/pain, dizziness, something stuck in the throat, tachycardia, and tingling of extremities (Table 2). Also, the patients who had experienced serious medical conditions, such as cancer or asthma, were at increased risk of developing an anxiety disorder. ${ }^{10,12}$

Ten patients complained of difficulty with inspiration or made an inspiratory noise when they were dyspneic. It was suspected that many of these patients may have been suffering from vocal cord dysfunction, which also is recognized as being amenable to therapy with hypnosis. ${ }^{13}$ However, most of these patients were taught self-hypnosis without a definitive diagnosis of vocal cord dysfunction, which is typically made definitively by visualization of adducted cords using nasopharyngeal fiber-optic laryngoscopy during an acute episode. ${ }^{14}$ Because use of hypnosis was associated with rapid resolution of symptoms of most of these patients, there was no need to undertake additional investigations, such as exercise pulmonary function testing for provocation of symptoms and/or laryngoscopic evaluation.

Although resolution or improvement of dyspnea cannot be attributed solely to hypnosis in this report, it seems that introduction of hypnosis was a key factor in view of the average 2-year duration of symptoms before its utilization. For the 4 patients who were symptomatic for a short duration (ie, for $<6$ months) it is possible that their improvement was caused by factors independent of hypnotherapy, such as change of weather or the conclusion of a sports season. Future studies are required to delineate whether, for example, reassurance of dyspneic patients without use of hypnosis is sufficient to achieve resolution of the symptom. Additionally, future studies might use objective scales to assess hypnotizability and to measure changes in dyspnea or anxiety and standard diagnosis and management protocols before introduction of hypnotherapy. These studies also might control for the patients' 
diagnoses, symptoms, age, activity level, and time of year.

The entrance criteria for patients in this report included chronic dyspnea despite appropriate medical therapy and normal baseline pulmonary function testing. Thus, patients with diagnoses, such as asthma, cystic fibrosis, and gastroesophageal reflux, were included if they complained of dyspnea and had normal lung function. The improvement in the symptoms of these patients underscores that patients with known medical diagnoses may develop symptoms amenable to psychological therapy, as has been reported previously.9,12 Furthermore, normal lung function does not always preclude pulmonary disease. Therefore, it is imperative that patients undergo an adequate medical evaluation before introduction of hypnotherapy to not obscure a diagnosis.

Many patients in this report may have benefited from psychotherapeutic interventions such as behavioral or pharmacological therapy. ${ }^{15}$ Nevertheless, hypnosis might be used first in this patient population, given the improvement rate after a typical total instruction time of $<1$ hour for each patient in this report.

\section{CONCLUSION}

A controlled prospective study using serial objective measures is recommended to substantiate this reported dramatic improvement of chronic dyspnea in pediatric patients who were taught self-hypnosis.

\section{REFERENCES}

1. Pratter MR, Curley FJ, Dubois J, et al. Cause and evaluation of chronic dyspnea in a pulmonary disease clinic. Arch Intern Med. 1989;149: 2277-2282

2. Sivraprasad R, Payne CB Jr. Nonpulmonary causes of dyspnea. Radiol Clin North Am. 1984;22:463-465

3. Olness K, Kohen DP. Hypnosis and Hypnotherapy With Children. 3rd ed. New York, NY: Guilford Press; 1996:87-132

4. Udolf R. Handbook of Hypnosis for Professionals. Northvale, NJ: Jason Aronson; 1987:55-88

5. Waxman D. Hartland's Medical and Dental Hypnosis. 3rd ed. London, England: Bailliere Tindall; 1989:19-36

6. Margolis CG. Hypnotic trance: the old and the new. Prim Care. 1997;24: 809-823

7. Gardner RM, Hankinson JL, Clausen JL, et al. Standardization of spirometry-1987 update. Am Rev Respir Dis. 1987;136:1285-1298

8. Knudson RJ, Lebowitz MD, Holberg CJ, et al. Changes in the normal maximal expiratory flow-volume curve with growth and aging. Am Rev Respir Dis. 1983;127:725-734

9. Aronoff GM, Aronoff S, Peck LW. Hypnotherapy in the treatment of bronchial asthma. Ann Allergy. 1975;34:35-62

10. American Psychiatric Association. Diagnostic and Statistical Manual of Mental Disorders: DSM-IV. 4th ed. Washington, DC: American Psychiatric Association; 1994:393-444

11. McNally RJ. Behavioral treatment of a choking phobia. J Behav Ther Exp Psychiatry. 1986;17:185-188

12. Bussing R, Burket RC, Kelleher ET. Prevalence of anxiety disorders in a clinic-based sample of pediatric asthma patients. Psychosomatics. 1996; 37:108-115

13. Martin RJ, Blager FB, Gay ML, et al. Paradoxical vocal cord motion in presumed asthmatics. Semin Respir Med. 1987;8:332-337

14. Newman KB, Mason UG, Schmaling KB. Clinical features of vocal cord dysfunction. Am J Respir Crit Care Med. 1995;152:1382-1386

15. Ferentz KS. Panic disorder and agoraphobia: nondrug treatment options for primary care physicians. Postgrad Med. 1990;88:185-192 


\section{Self-Hypnosis for Management of Chronic Dyspnea in Pediatric Patients \\ Ran D. Anbar}

Pediatrics 2001;107;21-

DOI: 10.1542/peds.107.2.e21

This information is current as of October 13, 2006

$\begin{array}{ll}\text { Updated Information } & \text { including high-resolution figures, can be found at: } \\ \text { \& Services } & \text { http://www.pediatrics.org/cgi/content/full/107/2/e21 } \\ \text { References } & \text { This article cites } 11 \text { articles, } 3 \text { of which you can access for } \\ & \text { at: } \\ \text { http://www.pediatrics.org/cgi/content/full/107/2/e21\#BIB } & \begin{array}{l}\text { Information about reproducing this article in parts (figures, } \\ \text { tables) or in its entirety can be found online at: } \\ \text { http://www.pediatrics.org/misc/Permissions.shtml }\end{array} \\ \text { Permissions \& Licensing } & \begin{array}{l}\text { Information about ordering reprints can be found online: } \\ \text { http://www.pediatrics.org/misc/reprints.shtml }\end{array}\end{array}$

\section{American Academy of Pediatrics}

DEDICATED TO THE HEALTH OF ALL CHILDREN ${ }^{\mathrm{m}}$ 